\title{
Las políticas de empleo y de conciliación laboral y familiar en el paradigma sueco
}

María José Vicente Vicente ${ }^{1}$

Recibido: 12/12/2020 / Aceptado: 25/03/2021

Resumen. Este artículo se basa en un trabajo de campo sobre el modelo nórdico centrándonos en el paradigma sueco, valorando sus diversas políticas de empleo situando a los municipios como proveedores de servicios, con el objetivo de conocer también la participación municipal en la política estatal del mercado laboral. En el mismo análisis resaltamos el enfoque en las políticas de empleo de la conciliación laboral y familiar, lo que hace de Suecia un país singular con respecto a otros países europeos.

Palabras clave: empleo; municipalismo; conciliación; familia; Estado de Bienestar.

\section{[en] Employment and work-family reconciliation policies in the Swedish paradigm}

Abstract. This article is based on a field work on the Nordic model, focusing on the Swedish paradigm, evaluating its various employment policies, placing municipalities as service providers, with the aim of also knowing the municipal participation in state labor market policy. In the same analysis, we highlight the focus on employment policies on work-life balance and family, which makes Sweden a unique country compared to other European countries.

Keywords: job; municipalism; conciliation; family; Welfare State.

Sumario. 1. Introducción; 2. Metodología; 3. El papel del municipalismo en las políticas de empleo; 4. Las políticas de empleo en Suecia; 5. Las políticas de conciliación en Suecia; 6. Conclusiones. Bibliografía.

Cómo citar: Vicente Vicente, M. (2021): Las políticas de empleo y de conciliación laboral y familiar en el paradigma sueco, en Cuadernos de Gobierno y Administración Pública 8-1, 25-34.

\section{Introducción}

La política laboral sueca se basa en una doble vertiente: por un lado, en medidas activas como los programas de mercado de trabajo y por otro, en la ayuda pasiva a los desempleados -en formación de prestación desempleo o pensiones de jubilación anticipada-. Los programas consisten, fundamentalmente, en trabajos para aliviar el desempleo y dotar de formación para el mercado de trabajos y también, en determinadas medidas selectivas orientadas especialmente hacia los jóvenes y las personas con discapacidad.

El volumen de las medidas de empleo activas hacía de Suecia uno de los primeros países de Europa tanto por el gasto como por el número de participantes en los programas de mercado de trabajo. Por otro lado, el permiso parental es también un tema de discusión constante en la agenda política de Suecia, abordando en este artículo el origen de las políticas públicas sobre natalidad y conciliación, aquellas que lograron que, por primera vez, se debatiera de forma científica sobre natalidad y conciliación y sobre ayudas a familias monoparentales dentro de la política social. Suecia se caracteriza por una consideración de la madre monoparental como trabajadora. Para ello se aborda tanto el legado institucional en la política familiar como en el tratamiento de la monoparentalidad. Este país registra en las últimas décadas un incremento de las familias monoparentales, pero a su vez su participación en el mercado laboral ha sido también elevada.

Finalmente, se describen los programas institucionales actuales, tras hacer un barrido histórico, que pone de relieve el desarrollo de estas políticas familiares, en aras de una mayor igualdad entre sexos y el reconocimiento 
de la monoparentalidad para asegurar el ejercicio de sus derechos en los permisos de parentalidad.

\section{Metodología}

Este estudio se basa en un análisis de contenido de diversa documentación académica y legislativa referida a las políticas de empleo y de conciliación laboral y familiar desarrolladas en Suecia, que cuenta con uno de los niveles de fecundidad más altos de Europa, con una tasa de fecundidad de 1,85 hijos por mujer en 2020y una tasa de natalidad (número de nacimientos por cada mil habitantes en un año) del 11,4\%o (frente a 1,31 hijos por mujer y una tasa de natalidad del 7,94\% en España) ${ }^{2}$.

\section{El papel del municipalismo en las políticas de empleo}

Las mancomunidades de municipios ("Kommuner") tienen una amplia competencia y están activas en varias áreas que contribuyen a la implementación de la política estatal del mercado laboral. Las responsabilidades de las kommuner incluyen las partes básicas de la vida de una persona, como vivienda y escuela primaria y educación secundaria para asegurar el apoyo básico, como también promover la contribución municipal a la política del mercado laboral desarrollando estrategias en crear comunidad empresarial local. Recientemente, el Gobierno ha encargado al Servicio Público de Empleo de Suecia que preparase y analizase ciertas condiciones para la reforma de este organismo, subrayando el papel de las mancomunidades de municipios como prestadoras del servicio de empleo facilitando la entrada de personas en el mercado laboral. Para ello, se garantiza una coordinación efectiva entre los municipios, a partir de estructuras ya existentes mientras se adaptan estas estructuras a las condiciones de diferentes municipios (atendiendo a condiciones locales y prioridades políticas) incluyendo en sus servicios tanto el apoyo a los buscadores individuales de trabajo como la colaboración en cuestiones estratégicas, procurando ciertos servicios bajo la Ley de Contratación Pública.

Entre las iniciativas municipales también se destacan las actividades de búsqueda de empleo y que las mancomunidades diseñen políticas de ayuda a los residentes municipales desempleados para un empleo subsidiado o regular, dejando un espacio relativamente grande para que los municipios puedan participar como contratistas del Servicio Público de Empleo estatal. Tales poderes vienen recogidos en la Ley de Gobierno Local y en la legislación especial adicional que desarrolla en la práctica lo que está determinado por la Ley, variando los poderes según el esfuerzo o la medida y dónde y cuándo se realiza.

A principios de 2020, menos de la mitad de los kommuner tenían una oficina de servicio de empleo pero

Datos extraídos del Banco Mundial y del Índice Coyuntural de Fecundidad 2020 su objetivo para finales de 2020 es el de garantizar la presencia en todo el país, diferenciando entre esfuerzos de correspondencia, que son los destinados a personas que están cerca de conseguir un trabajo y los esfuerzos de equipamiento, que son los destinados principalmente a personas que están más alejadas del mercado laboral. Donde más esfuerzos se realizan desde el ámbito mancomunal es en la formación del desempleado, ya que los municipios son responsables de la Educación de sus adultos, destacando que el total del gasto público para el sistema educativo supone aproximadamente un 7,5\% del PIB, lo que hace que Suecia sea uno de los países que más invierte en Educación, mientras la media europea es de un $5,8 \%$.

La formación en el mercado laboral se ha llevado a cabo de forma privada desde la mitad de la década de 1980. Los actores privados que colaboran con los servicios del mercado laboral han sido parte de la política sueca del mercado laboral desde 2007. Los contratistas externos representan actualmente una parte importante de las iniciativas que el Servicio Público de Empleo de Suecia ofrece a los solicitantes de empleo que están registrados. En 2019, aproximadamente 61.000 personas desempleadas participaron en servicios de empleo con actores independientes contratados por el Servicio estatal de Empleo Público y 46.000 desempleados participaron en la formación adquirida y de ahí consiguieron sus trabajos.

En 1997 se puso en marcha un sistema especial de asistencia educativa que permite a las personas en paro seguir una educación básica o secundaria, durante máximo un año, al tiempo que reciben una suma equivalente a la prestación contributiva por desempleo o al subsidio asistencial.

Como parte de los programas gubernamentales activos de mercado de trabajo, se ofrece formación profesional a las personas en paro o amenazadas con perder su puesto de trabajo. Las actividades de formación y reciclaje se organizan a través de la Agencia Nacional de Formación para el Empleo (AMU), que coordina unos 100 centros de formación.

Además de la Ley de Gobierno Local, existen otras regulaciones que rigen lo que los municipios y mancomunidades pueden hacer y que son importantes para el área del mercado laboral. Según la Ley de la Junta de Desempleo (Rundström, 2020: 30), los municipios tienen la tarea de prevenir el desempleo en su propio municipio y reducir sus efectos; también, en las áreas de servicio social y educación.

Con el apoyo de la Ley de Servicios Sociales, los municipios tienen la obligación de promover el derecho de las personas a trabajar (Capítulo 3, Sección 2 de la Ley de Servicios Sociales).

La presencia física del servicio de empleo en todo el país ha ido disminuyendo. Durante el período 20142018, el Servicio Público de Empleo de Suecia cerró sus operaciones locales en 60 municipios.

A principios de 2014, el Servicio Público de Empleo tenía oficinas en 278 de los 290 municipios de Suecia. Cuatro años después, había oficinas en 218 municipios. En poco menos de un tercio de estos municipios, había 
una oficina de servicios de empleo que estaba abierta todos los días laborables de la semana. Según el Servicio Público de Empleo de Suecia, las principales razones del cierre de oficinas durante estos años han sido el cambio en los métodos de trabajo y la digitalización.

Entre enero de 2019 y enero de 2020, se cerraron las oficinas en otros 84 municipios y en enero de 2020, 134 de los municipios del país tenían una oficina de Empleo. De acuerdo con los últimos acuerdos legislativos que el gobierno quiere poner en marcha, el Servicio Público de Empleo habrá de garantizar la asistencia en todo el país pero con una colaboración entre redes de municipios para que funcione de manera más eficiente, trazando de manera clara la división de responsabilidades entre Estado y municipio. La proporción de personas desempleadas que están lejos del mercado laboral ha aumentado y muchas de estas personas desempleadas reciben su apoyo a través de la asistencia financiera de los municipios, con la ayuda de una planificación individual coordinada, contribuyendo a un aumento constante del empleo a largo plazo y situando al municipio como contratista en nombre del Servicio Público de Empleo de Suecia.

Se procura que estas actividades del Servicio de Empleo supongan un diseño equivalente para empleadores y demandantes de empleo en todo el país y todo ello adaptado a las condiciones y necesidades en diferentes partes del país, con programas de colocación laboral, orientación, formación, reinserción y actividades enfocadas a jóvenes con discapacidad (llevar a cabo actividades comerciales donde las personas con discapacidad tengan la oportunidad de empleo) estableciendo un plan de acción individual con el solicitante de empleo, separando entre las áreas de política social, educativa, de integración y de política empresarial y tratando de reunir de manera efectiva a quienes ofrecen trabajo con quienes buscan trabajo. Entre ellos, hay tres listas prioritarias: la educación municipal para adultos, la orientación comunitaria para inmigrantes recién llegados y la orientación para la actividad laboral para los jóvenes menores de 20 años que no han empezado a trabajar y no han comenzado o completado una educación secundaria superior, con el objetivo de reducir el desempleo juvenil.

Como la educación es una parte importante de la política del mercado laboral, las personas que no tienen educación secundaria son candidatos más difíciles para obtener empleos y las mujeres en este grupo tienen una posición particularmente débil el mercado laboral. En 2018, el desempleo fue de poco más del 20\% entre personas que no tenían educación secundaria, que se puede comparar con una tasa de desempleo de poco menos del 4 por ciento entre aquellos con educación postsecundaria. Poco más de un tercio de los desempleados que se registraron en el Servicio Público de Empleo de Suecia en 2019 carecían de educación secundaria superior. Las personas desempleadas que carecen de una educación equivalente a la escuela primaria están aumentando también. Equipar a los solicitantes de empleo con las habilidades adecuadas es central para un buen funcionamiento de la política del mercado laboral. La importancia de la educación de adultos en la oferta de habilidades se aclara en la Ley de Educación. Las guías inscritas en educación dentro de la educación municipal para adultos es una forma en que el Servicio Público de Empleo de Suecia puede contribuir a que los desempleados participen en iniciativas educativas, separando entre adultos de nivel básico, de secundario y de superior.

La iniciativa municipal temprana se basó en la responsabilidad municipal por la atención deficiente y los costes de la atención de emergencia para los pobres. Los primeros servicios municipales de empleo se establecieron en 1902 y desde 1907, el Estado otorgaba subvenciones para diversas actividades con la condición de que las oficinas municipales de empleo tendrían un uniforme método de trabajo en todo el país. Durante aproximadamente 40 años, el servicio de empleo estuvo a cargo de municipios y kommuner (consejos de condado; buscando su equivalente en España, mancomunidades de municipios). Bajo el liderazgo municipal, los planes de Empleo han consistido principalmente en tres tareas: colocación laboral, control de desempleo y estadísticas. No fue hasta 1940 cuando Suecia consiguió una organización estatal para servicios de empleo, integrando las juntas laborales del condado (de las kommuner, activas hasta 2008) con el objetivo de dirigir y de coordinar las oficinas locales, asumiendo posteriormente sus competencias el Servicio de Empleo estatal "Arbetsförmedlingen". Una gran parte de los ingresos municipales para medidas del mercado laboral son remuneraciones del Servicio Público de Empleo de Suecia a los municipios.

En el mercado laboral, el Servicio Público de Empleo de Suecia reemplaza a los municipios en el pago a los desempleados que participan en la capacitación laboral. Los municipios también pueden recibir una compensación por las actividades de búsqueda de empleo y estudio u orientación profesional para desempleados dentro de los Planes de Garantía Juvenil de Empleo. En general, los participantes en iniciativas municipales son mayores receptores de asistencia financiera que los que participan en el Servicio de Empleo público estatal y también hay una mayor proporción de personas poco cualificadas que participan en iniciativas municipales.

La formación en el mercado laboral se ha llevado a cabo de forma privada desde la mitad de la década de 1980. El propósito de habilitar a los contratistas externos fue para promover la flexibilidad en las iniciativas de capacitación y una mejor gestión de los recursos. En promedio, cada oficina tiene a 19 empleados a tiempo completo trabajando en los problemas del mercado laboral.

\section{Las políticas de empleo en Suecia}

La política de empleo se basa en el principio de activación destinándose un amplio porcentaje a programas de activación del mercado de trabajo rozando un 50\% del gasto total en materia de política de mercado de trabajo. Desde 1993, están permitidas las agencias de empleo con fines lucrativos; sin embargo, está prohibido solicitar cuotas a los empleados y sólo les está permitido cobrarlas a los empresarios. 
La participación laboral de la mujer sueca es elevada en comparación con la participación de la misma en otros Estados miembros de la UE: un $78 \%$, frente a una media europea de un 57\% y aproximadamente la mitad de la población activa sueca está constituida por mujeres. En Suecia, la tasa de desempleo para mujeres es inferior a la de los hombres, como veremos posteriormente, lo cual resulta curioso dado que, en la mayoría de los países europeos, las tasas de desempleo para mujeres son más elevadas que para los hombres.

Dentro de las estrategias de empleo, cabe hablar de la importancia de las centrales sindicales suecas, con un alto porcentaje de participación de los trabajadores, cifrándolo en torno a un 90\%. Los tres sindicatos mayoritarios son la Confederación Sueca de Sindicatos (LO), que reagrupa a 21 organizaciones sindicales y cuenta con más de 2 millones de afiliados; la Confederación Sueca de Trabajadores Profesionales (TCO), con casi un millón y medio de miembros y la Confederación Sueca de Asociaciones de Profesionales (SACO), que cuenta con cerca de medio millón de miembros. Aproximadamente, la mitad de la población activa sueca está constituida por personal administrativo, mientras que la mayor parte de los miembros de la Confederación LO trabaja fuera del sector industrial.

Las organizaciones LO y TCO se basan en el principio industrial, según el cual los sindicatos se organizan por sector económico en lugar de por la actividad profesional de los empleados. Los empleadores pagan el 0,3\% de su nómina total a los consejos de seguridad laboral, como una póliza de seguro contra despidos. Cuando la situación económica es buena, el dinero se acumula; luego, cuando existe la necesidad de reducir el tamaño de las plantillas, los consejos están allí para mitigar el golpe, cubriendo un asesor personal para quien pueda ser despedido próximamente y así ayudar a poder encontrar un nuevo puesto de trabajo en las personas afectadas. Sobre un $90 \%$ de los trabajadores que son despedidos vuelven a tener empleo en un plazo de seis meses. También, los empresarios disponen de un alto nivel de organización. Las organizaciones más importantes son la Confederación Sueca de Empresarios (SAF) para el sector privado, la Asociación Sueca de Autoridades Locales, la Federación de Diputaciones Provinciales y la Agencia Sueca de Funcionarios (AgV). La principal de estas organizaciones es la SAF, que representa a 42.000 compañías del sector privado, con un total de 1,3 millones de trabajadores (Forsäkringskassan, Europarl: 1994).

En Suecia, los acuerdos colectivos han desempeñado tradicionalmente un papel esencial en la regulación de las relaciones entre empresarios y trabajadores. Los acuerdos colectivos abarcan cualquiera de los aspectos de la relación entre empresario y trabajador, como por ejemplo los salarios, las condiciones laborales, así como los términos y las condiciones de contratación. Incluso, aunque exista legislación sobre un determinado ámbito, esto no impide la conclusión de acuerdos colectivos, partiendo siempre de que dichos acuerdos garanticen una posición mejor que la prevista en las disposiciones legales.
Habitualmente, la negociación se producía a nivel central, en las que ambas partes negociaban en nombre de sus respectivos afiliados. Sin embargo, desde 1983, con el Gobierno de Olof Palme, las negociaciones en el sector privado se han ido descentralizando y éstas se producen cada vez con más frecuencia a nivel de sectores. La Confederación de Empresarios (SAF) se opone abiertamente a que las negociaciones sobre cuestiones salariales se realicen a nivel central.

El éxito de la política de los sindicatos en materia de equiparación salarial puede verse claramente en las escasas diferencias salariales existentes en Suecia en comparación con las habituales en otros países de la OCDE. Mientras que la diferencia salarial entre las categorías de trabajadores dentro del sector industrial, a comienzos de la década de los 80 , era de un 34\% en Suecia, en el Reino Unido esta diferencia alcanzaba el $210 \%$ y en los Estados Unidos el 490\% (OECD, Economic Surveys Sweden, 1994).

Gracias al "compromiso de paz" existente entre las organizaciones de empresarios y los sindicatos, que data del denominado Acuerdo Saltsjöbaden de 1938, en Suecia se convocan pocas huelgas y son escasos los días que se pierden en las mismas -la media anual es de 100 por cada 1.000 empleados entre 1988 y 1992- mientras que la media anual del EEE es de 153.

Con la adhesión en 1995 de Suecia a la UE, previamente el Gobierno sueco se aseguró, a través de la Comisión Europea, de que el Protocolo Social del Tratado de la UE no supondría ningún cambio de las prácticas existentes internamente en el país en materia de mercado de trabajo y más concretamente, de su sistema de acuerdos colectivos entre los interlocutores sociales.

La legislación sueca no prevé ningún tipo de salario mínimo, sin embargo, las retribuciones salariales mínimas se establecen en los acuerdos colectivos y desde la crisis económica de 1991, el sistema de pensiones fue modificado para poder garantizar su sostenibilidad, dándose tres tipos de pensiones: 1) Garantipension: para quienes no alcancen las cantidades que el Estado estima que son necesarias para vivir; 2) Ikonstpension: sistema de capitalización individual con planes de pensiones de empleo y 3) Premiepension: Lo que forma el sistema individual de pensiones. Las cuentas nocionales tratan de un sistema de prestación indefinida, que funcionan como los planes de pensiones privados, donde se toma en cuenta todo lo aportado a la Seguridad Social durante toda la vida laboral, calculándolo con respecto al dato de la esperanza de vida en el momento de jubilarse. Contrasta con el sistema de reparto que hay en España.

El conjunto de la legislación en materia de mercado laboral en vigor hoy día en Suecia data de comienzos de la década de los 70 como, por ejemplo, las leyes en materia de participación de los trabajadores en la toma de decisiones sobre cuestiones relacionadas con la vida laboral, la seguridad en el trabajo y el estatuto de los representantes sindicales en el lugar de trabajo.

Según la Ley sobre las Vacaciones Anuales, todos los empleados tienen derecho a un mínimo de 25 días laborables, esto es, a cinco semanas de vacaciones anuales. 
La Ley sobre Seguridad del Empleo protege a los trabajadores contra el despido improcedente, lo que supone que el empresario deberá alegar motivos objetivos para dicho despido. Un motivo objetivo de despido, por ejemplo, es la falta de trabajo, que haga posible prescindir de una o más personas. Sin embargo, si el trabajador puede ser transferido a un puesto distinto dentro de la misma compañía, no debe procederse al despido. Por lo general, los despidos se rigen por el principio de que los últimos contratados son los primeros en ser despedidos.

Los empleadores tienen obligación de informar a sus empleados del desarrollo de la producción de la empresa, del estado de su economía, y sobre las directrices de las políticas de personal de la empresa. Cuando un empresario prevé cambios significativos en las actividades de la empresa o en las condiciones laborales para uno o varios miembros de las sindicales, tiene la obligación de consultar con los empleados ante de tomar ninguna decisión. En empresas privadas con al menos 25 empleados, éstos tienen derecho a representación en el consejo administrativo Forsäkringskassan, Information on Social Security, 1994).

5. Las políticas de conciliación en Suecia

A principios de siglo XX, en Suecia las viudas recibían ayudas económicas para pobres, poor relief, mientras que las madres solteras eran confinadas en casas de pobres o bien eran obligadas a dejar a sus hijos en orfanatos (Madruga, 2006: 110). En pocos años en Suecia se experimenta un gran avance social destacando como uno de los primeros países en promulgar medidas legales para las madres separadas, solteras y abandonadas en una época en que las cuestiones morales desempeñaban un papel importante. Por tanto, en estudios constantes sobre opinión pública, puede constatarse que las familias monoparentales no sufrieron el rechazo de la sociedad sueca (Wennemo, 1984: 85).

Cuando se analiza la ruptura matrimonial desde un punto de vista histórico hay que destacar que el sistema nórdico era menos rígido que el de otros países europeos. En la década de 1920, el divorcio incluía una amplia variedad de motivos entre los que se encontraban el mutuo acuerdo y la ruptura de las relaciones maritales (Goode, 1993), entendiéndose el divorcio como resultado de una serie de problemas personales y sociales y no como una crisis de la moral individual.

En cuanto a la custodia compartida tras el divorcio, entonces era suficiente la oposición de uno de los progenitores para negar la custodia compartida. En cambio, en la actualidad, en un $80 \%$ de los casos, los padres siguen teniendo este tipo de custodia tras el divorcio, pero esto no siempre implica que un hijo viva, en parte, con el padre y, en parte, con la madre; en nueve de cada diez casos, vive con la madre ${ }^{3}$.

Además, Suecia, su Estado, ha mostrado históricamente un carácter pionero ante los hijos no matrimoniales. Desde principios de siglo se desarrolló un individualismo igualitario, a través del cual se instauró la igualdad entre el marido y la esposa. Los países escan-

El Instituto Sueco, "Estadísticas y encuestas de opinión pública", material de Swedish Institute, disponible en https://si.se/en/, 2000 y ss. dinavos, con Suecia a la cabeza, eran menos patriarcales que otras sociedades porque eran luteranos. Pero esto no implica que el luteranismo fuera menos patriarcal que otras religiones; lo que ocurría era que, en esta época, el luteranismo se había convertido en menos ortodoxo y eso favorecía a los niños y las mujeres. Esta igualdad se extiende en el reconocimiento de derechos entre los hijos matrimoniales y extramatrimoniales ${ }^{4}$. Se instituyó la igualdad de derechos de paternidad, aunque inicialmente no una igualdad en los derechos de herencia, hasta llegar al año $1954^{5}$ y extenderse a todos los hijos los mismos derechos de herencia. Ya en 1976 se elimina definitivamente esta distinción (Therborn, 1993:258-259), identificándose entre los suecos actitudes más liberales hacia el fenómeno de la cohabitación desde principios del siglo $\mathrm{XX}^{6}$.

La preocupación por el descenso de la población en Suecia y por el bienestar de las familias con hijos, en las primeras décadas del siglo XX se había circunscrito a los círculos políticos conservadores, que temían el impacto del declive poblacional en su fuerza laboral y en su poder militar (Madruga, 2006). En los años treinta y cuarenta, un encendido debate ocupó la escena política sueca en torno a la cuestión de si las familias con hijos debían recibir deducciones fiscales o prestaciones familiares ${ }^{7}$. Tanto los conservadores como los partidos agrarios favorecían las deducciones fiscales, mientras que los socialdemócratas y los liberales apoyaban las prestaciones familiares. Los socialdemócratas lideraron el discurso de la reducción de la desigualdad entre clases sociales como vía de proporcionar amparo a los niños.

Las propuestas de los Myrdal se diferenciaban de las políticas conservadoras de países como Francia y Alemania en que combinaban dos objetivos aparentemente contradictorios: fomentar la natalidad y el control de la misma. Myrdal no pedía que la mujer volviera a su tradicional papel de ama de casa; al contrario, ponía el énfasis en hacer más fácil tener hijos a las madres trabajadoras. De acuerdo con Popenoe (Popenoe, 1988), la novedad que se introduce en la escena política sueca es la consideración de que la carga económica de la educación y crianza de los hijos debía pasar del individuo a la sociedad, hablando por vez primera de que la familia es la principal institución de la sociedad, lejos de las disquisiciones morales planteadas por la Iglesia, aunque esta manera de ver a la familia eran opuestas a corrientes "antifamilialistas", que criticaban a la familia burguesa victoriana que había emergido en el siglo XIX y cuyos exponentes los vemos en intelectuales que ven a la familia como opuesta al desarrollo personal y a la libertad del individuo (visión defendida por el feminismo) y por otro lado, en los marxistas, que también ven en la familia un lugar de opresión. Frente a esto, el mérito de Alva

Swedish Marriage Act de 1915.

1954 års lag om moderskapshjälp (Ley de 1954 sobre Asistencia a la Maternidad).

En la actualidad, las relaciones económicas de quienes cohabitan se encuentran reguladas en la Joint Home Act (Ley de Hogares Unidos). Betänkande angående moderskapspenning och mödrahjälp avgivet av Befolkningskommissionen (Informe sobre el estrés materno y sobre asistencia a la maternidad proporcionado por la Comisión de Población en 1936). 
Myrdal y otras feministas fue introducir en el debate político la cuestión del derecho de una mujer trabajadora a casarse y tener una familia (Gustafsson, 1995: 296) .

A medida que evolucionaba la política familiar sueca se consiguió fusionarla con una política de clase y una política de género. El proyecto del Estado de Bienestar desarrollado a partir de los años sesenta en Suecia asignaba una mayor responsabilidad estatal en el cuidado de los niños, ancianos, enfermos y discapacitados (Popenoe, 1988: 124). La idea no es maximizar la dependencia de la familia, sino las capacidades individuales para conseguir la independencia (Esping-Andersen, 1990). En el caso sueco, la satisfacción de las necesidades de cuidados y de servicios personales se han repartido entre la familia y el Estado de Bienestar. No hay que olvidar que antes del desarrollo del Estado de Bienestar la mayoría de estos servicios eran proporcionados por la mujer dentro de la familia y que la familia sueca se marca como ideal que hombre y mujer por igual deben poder trabajar para mantenerse.

Las relaciones económicas entre los esposos están reguladas por el Código del Matrimonio de 1987 que, entre otras cosas, expone que no hay derecho a la pensión compensatoria tras una separación. Para los hijos es diferente y está regulado en el código parental (Björnberg y Björk, 1995). También contiene enmiendas al Código de Sucesiones, destinadas a reforzar la posición del cónyuge económicamente más débil en caso de divorcio o fallecimiento del otro cónyuge. La responsabilidad en la socialización de los hijos es compartida por los padres y el sector público (Bjönberg, 1992: 8). El Estado garantiza el derecho de ser padre/madre y, al mismo tiempo, controla la forma en que este derecho se realiza.

En cuanto al indicador de número de divorcios se observa la misma tendencia creciente. En la década de los cincuenta se producían 1,18 divorcios por cada 1.000 habitantes (Goode, 1993: 84). En 1960, este número de divorcios ascendía a 1,2 por mil habitantes ${ }^{9}$. Aunque ya en la década de los sesenta Suecia tenía niveles medios de ruptura matrimonial, fue a partir de la simplificación de la ley de divorcio en 1973-1974 cuando se aceleraron los cambios y aumentó el número de familias monoparentales. El factor principal que explica el aumento del número de divorcios en el período 1961-1983 fue la liberalización de la ley de divorcio (Castlesy y Flood, 1994: 24), una tendencia que ha continuado al alza posteriormente, aunque el perfil de las familias ha ido cambiando con el transcurso del tiempo, perdiendo peso las viudas ${ }^{10}$ a favor de las divorciadas y madres solas (Hoem y Hoem, 1992: 281). Así, una alta participación laboral de las mujeres mayores de 45 años señala una necesidad latente de prestaciones para la baja parental o los servicios de atención a la infancia, al no poder estas mujeres hacerse cargo de los sus hijos. También, se

También se la considera pionera en introducir en el debate político la importancia de la inclusión de la educación sexual en las aulas.

9 Eurostat database (1995 y ss.) Disponible en https://ec.europa.eu/ eurostat/data/database

10 Desde 1990, en Suecia no existe la pensión de viudedad. Se justificó como forma de que las mujeres no dependan de la vía del matrimonio y sí de ser activas laboralmente para tener su encaje en la sociedad. apostó políticamente por una convergencia en las tasas masculina y femenina de participación en el empleo. Mientras que en 1983 la participación femenina llegaba al 80,6\% frente al 90,2\% de los hombres, en 1991 la participación laboral de las mujeres subió al $84,9 \%$ frente al 90,1\% de los hombres (Hoem y Hoem, 1992: 281). Y en 1998 , un $74 \%$ de las mujeres entre 20 y 64 años tenían un trabajo remunerado, en comparación con un $79 \%$ de los hombres. Será en la década de los ochenta cuando las obligaciones familiares no supongan diferencias en la participación laboral de la mujer. Así, en 1982, un $83,7 \%$ de las mujeres participaba en el mercado laboral, un $83,5 \%$ de las mujeres casadas y un $80,6 \%$ de madres con hijos menores de siete años (Gustafsson y Jacobsson, 1985: 259).

En la década de 1950 se institucionalizaron los programas de vivienda, de empleo y prestaciones constantes tales como la pensión alimentaria, la baja de maternidad, los servicios de atención a la infancia y otras prestaciones de familia. En esa década, el divorcio pasa a ser un asunto privado y es en 1974 cuando se establece el $d i$ vorcio ruptura. De acuerdo con él, si las dos partes están de acuerdo y no hay hijos menores de 16 años, hay un reconocimiento automático de su derecho al divorcio; si no es así, la ley fija un periodo de reflexión de 6 meses.

Con respecto al anticipo de la pensión alimentaria, ya con la Ley de 1964, se estableció una cantidad mínima en lugar de los acuerdos individuales negociados en los tribunales, garantizando a todos los niños un mínimo de subsistencia. No sólo se proporcionaba una seguridad económica básica para los niños con un progenitor ausente, sino que, al mismo tiempo, se transfería parte de la responsabilidad recaudatoria del progenitor por la custodia en el Estado (Garfinkel y Sörensen, 1982: 513).

Las décadas de 1960 y 1970 son, según algunos autores, la fase de expansión de los servicios sociales en Suecia (Olsson, 1993: 16) ${ }^{11}$. En los sesenta se produjeron los debates más interesantes en torno a la política familiar ${ }^{2}$. Y también son estas dos décadas las más importantes en el desarrollo e implementación del conjunto de políticas familiares de monoparentalidad ${ }^{13}$. El compromiso público con el principio de la igualdad de géneros y la importancia concedida a la actividad económica como una forma de conseguir la primera han sido elementos clave en la historia de la participación de las mujeres en el mercado laboral. Así lo destacan, entre otros investigadores, Britta Hoem y Jan Hoem (1993). En los años 1960 se produce la expansión de los servicios públicos de escuelas infantiles (Sundstróm, 1991).

El "Informe Erlander", que toma su nombre del primer ministro socialdemócrata sueco ${ }^{14}$, se publica en

11 Stöd åt barnaföderskor: betänkande 1 avgivet av Socialpolitiska kommittén (Apoyo a la natalidad: Informe 1 presentado por el Comité de Política Social)

12 "Ökat stöd till barnfamiljer"; promemoria avgiven av Familjeberedningen ("Mayor apoyo para familias con niños"; memorando dado por el Consejo Asesor de la Familia en 1964).

13 Familjestöd: betänkande avgivet av Familjepolitiska Kommittén (Apoyo familiar: informe presentado por el Comité de Política Familiar en 1972).

14 Tage Erlander es el jefe de gobierno que más tiempo ha permanecido en su mandato en una democracia, de 1946 a 1969 (23 años). 
1964 y supone que, por primera vez en la historia, el partido socialdemócrata defenderá una visión integral de la situación de cada individuo que incluye su estatus como miembro de una unidad familiar, el respeto a su individualidad y la igualdad de género como parte importante en sus aspiraciones para conseguir la igualdad entre todos los ciudadanos. En este periodo se desencadenó una discusión pública en tono a los roles de género en la sociedad sueca. Este debate penetró tanto en la política familiar, como en la educativa y en la del mercado laboral (Liljeström, 1978). El elemento central de dicho debate giraba en torno al papel de la política social como promotora de determinadas estructuras familiares. El informe Erlander tuvo una gran influencia en el desarrollo legislativo de principios de los setenta. Una de las principales recomendaciones fue convertir el sistema de baja de maternidad en un sistema de baja parental. Esta sustitución implicaba mucho más que una simple variación semántica, estudiando las horas necesarias dedicadas al trabajo antes del nacimiento del hijo, los incentivos para el empleo y el nivel de las prestaciones (Nisman, 1992: 95). En este sentido, si la madre se encontraba estudiando y no tenía ningún ingreso perdía la oportunidad de compartir esta baja con el padre a menos que encontrara un trabajo después del nacimiento. Asimismo, era importante tener un trabajo antes del nacimiento de un segundo hijo al elevar la tasa de sustitución.

En 1974 se estableció una tasa de sustitución de la prestación de un $90 \%$ del salario y se introducía la novedad de compartir la baja con el padre ${ }^{15}$. Se consideraba así que una extensión de las bajas de maternidad a los hombres era una forma de simbolizar la igualdad entre los géneros, dando más oportunidades a los hombres para adquirir una mayor responsabilidad en el cuidado de los hijos (Haas, 1992: 401). Pero no sólo la baja parental, también la baja de paternidad y la baja para cuidar hijos enfermos permitía a padres y madres compartir la misma, con una ley en 1974 que concedía a los hombres la baja dentro del primer mes siguiente al nacimiento del hijo y permitió compartir con la madre 10 días de baja para cuidar de un hijo cuando éste se encontraba enfermo (Madruga, 2006: 132). Al mismo tiempo, desde 1974, el parental leave, se podía utilizar a media jomada hasta que el hijo cumpliera los ocho años (Sundström, 1991: 140).

La formulación de la política de cuidados del niño ha concernido tanto al gobierno central como a las autoridades locales. Mientras que el gobierno central ha sido el encargado de establecer los objetivos de esta política, las autoridades locales han sido las encargadas de ponerla en práctica. En 1975, una ley sobre educación preescolar obligaba a las autoridades locales a proveer plazas para todos los niños menores de seis años. De acuerdo con Ruggie (Ruggie, 1984), la secuencia en la intervención estatal en el área de los servicios de atención a la infancia ha sido determinada, en primer lugar, por un incremento de la participación de la mujer en el

\footnotetext{
15 Así vemos que es en 1974 cuando se introduce el seguro parental. Por primera vez, ambos padres tenían derecho a una compensación financiera por estar en casa con sus hijos.
}

mercado laboral; en segundo lugar, por las recomendaciones de las comisiones gubernamentales y finalmente, por las necesidades sociales específicas, en función del número de horas que los progenitores trabajaban y los ingresos que tuvieran. El discurso sobre el declive de la familia tradicional apenas ha tenido eco en la sociedad sueca, a diferencia de otras sociedades como la británica o la americana, donde ha venido asociado con altas tasas de dependencia de las familias monoparentales respecto de las prestaciones asistenciales (Hobson y Takahashi, 1997: 145).

En 1978 tanto padres como madres consiguieron el derecho a una baja no remunerada hasta que sus hijos cumplieran 18 meses, así como el derecho de reducir la jornada laboral a seis horas (Madruga, 2006). En 1980 se introdujo el subsidio de embarazo para mujeres gestantes; éstas, de acuerdo con la naturaleza del trabajo, podían abstenerse de seguir trabajando durante los dos últimos meses de embarazo sin necesidad de justificar enfermedad. De esta manera, se eliminó toda posibilidad de sufrir estrés en el embarazo, además de garantizar la no discriminación de las mujeres y la toma regular de tiempo libre antes del nacimiento del bebé. A principios de la década de los ochenta, entre los partidos socialdemócratas europeos comenzaron a perder fuerza las ideas del keynesianismo redistributivo en favor de términos de eficiencia económica. Conseguir un presupuesto equilibrado y una menor intervención estatal eran considerados requisitos imprescindibles para alcanzar la deseada eficiencia económica. En 1982, los socialdemócratas introdujeron cambios en la baja para cuidar a los hijos enfermos. Por un lado, aumentaron hasta 60 los días de disfrute, por otro, extendieron esta prestación a todas aquellas familias con hijos menores de doce años (Sundström y Stafford, 1992: 202). En 1988, los padres consiguieron tres meses más de baja parental, aumentando a doce los meses remunerados, al mismo nivel de compensación que el de enfermedad: en la mayoría de los casos, con el $90 \%$ de los ingresos y con una paga adicional mínima en los tres meses siguientes. Se consiguieron, de esta manera, tres meses más de baja parental remunerados. La seguridad en el empleo quedaba garantizada por un periodo de dieciocho meses. De acuerdo con esta legislación, los padres pueden utilizar el parental leave hasta que el hijo tenga ocho años.

Cuanto mayor es el salario de la mujer, es mayor la probabilidad de que el padre tome la baja parental (Nisman, 1992). En marzo de 1991, ante las altas tasas de absentismo, el gobierno decidió rebajar la tasa de sustitución de la baja para cuidar de los hijos enfermos de un 90 a un $70 \%$ para los primeros días y como consecuencia de este cambio, la tasa de absentismo disminuyó (Gustafsson, 1994: 304). Por otra parte, parece que los empresarios estaban a favor de este tipo de bajas y no veían ningún problema en el acogimiento de la baja parental que se tomaba a tiempo completo; solo unos pocos empresarios, de pequeñas empresas, expresaban problemas ante estas bajas. Como observa la Dra. Madruga, en su libro "Monoparentalidad y política familiar" (2006), hay determinados autores que consideran que una de las 
razones del éxito electoral de los socialdemócratas fue la percepción pública de la eficiencia económica y del bienestar social (Stephens, 1996: 45). Lo cierto es que han mostrado un apoyo decidido y generalizado a las políticas sociales y el Estado de Bienestar. Los servicios de atención a la infancia tenían en 1986 un apoyo mayoritario y las prestaciones asistenciales eran mucho menos populares. Este apoyo masivo es consecuencia del carácter universal de las políticas.

En medio de una fuerte crisis económica, en 1991 ganó las elecciones una coalición opuesta al Partido Socialdemócrata. Una de las propuestas principales consistía en detraer recursos del sistema de servicios de escuelas infantiles para asignar estos recursos a las familias con hijos menores de tres años en forma de prestaciones de cuidado. Se aprobó una ley por la cual las mujeres podían elegir entre un pequeño subsidio o los servicios de atención a la infancia municipales. En 1994, al recuperar el poder los socialdemócratas, defendiendo que la prestación de cuidado no era solidaria con las madres trabajadoras, lograron que se suprimiera (Hobson y Takahashi, 1997: 128). En la búsqueda de un seguro parental más igualitario, se introdujo en 1995 el llamado "mes del padre"16, que garantiza que madre y padre tienen un mes asignado que no se puede transferir ${ }^{17}$. En 2002, ese tiempo se extendió a dos meses.

Con el nuevo siglo y milenio, nos hemos ido enfrentando a una economía cada vez más globalizada. Desde principios del año 2000, en Suecia se concede a los padres, tras el nacimiento de un hijo, una baja parental con prestación económica durante un total de 450 días, de los que 420 pueden ser repartidos entre los progenitores como ellos quieran. Sin embargo, los otros 30 días, llamados "mes del padre", no pueden ser transferidos. A los padres que viven solos se les permite obtener esta baja en su totalidad. El nivel de remuneración es del $80 \%$ de los ingresos brutos durante 360 días. Para los 90 restantes se paga una cantidad fija diaria de 60 SEK (en torno a $6 €$ ). Las prestaciones pueden usarse de formas diversas: quedarse en casa a jornada completa o trabajar a jornada parcial durante un período más largo. Los padres sin trabajo remunerado anterior al nacimiento de un hijo reciben durante 450 días la cantidad fija diaria. Además de estas prestaciones, al nacer un hijo el padre tiene derecho a diez días de baja de paternidad. Cualquiera de los progenitores puede también obtener permiso para cuidar a un hijo enfermo con compensación por la pérdida de ingresos (60 días por año e hijo). Y para facilitar la conciliación del trabajo con la vida familiar, los que tengan hijos menores de ocho años tienen igualmente derecho a reducir su jornada laboral diaria en dos horas, con la reducción correspondiente de sueldo.

Durante la década de 2000, la política se ha centrado en la atención a los niños y a las familias con niños: se fijó una tasa máxima, un límite, sobre cuánto debe pagar una familia por su cuidado y también una regla de blo-

16 Föräldraledighetslagen (Ley de licencia parental de 1995).

17 Aquí vemos que es en 1995 cuando se reservase reserva un mes de seguro parental para cada padre. En 2002 se reservó un segundo mes para cada padre. En 2016 se reservó un tercer mes para cada padre. queo, de forma que la familia pagará un máximo del 3\% de sus ingresos en cuidado de niños para el primer hijo aumentándose el nivel de garantía del seguro parental desde los 120 SEK por día en 2002 (aprox. 11€), a 150 en 2003 (aprox. 14€) y a 180 SEK desde 2004 (aprox. $17 €)$. El número de días de beneficios parentales ha aumentado desde los 240 días en la década de 1970 a 480 días hoy. Las disposiciones sobre prestaciones parentales se encuentran en el Capítulo 4 de la Ley de Seguros Generales ${ }^{18}$. Si los padres tienen la custodia compartida del niño, ambos tienen derecho a la mitad del número total de días de beneficios parentales, pero uno de los padres puede transferir el derecho a la asignación parental al otro progenitor.

En los esfuerzos de Suecia para lograr la igualdad de género, cada padre tiene derecho a 240 de los 480 días de licencia parental remunerada. Cada padre tiene 90 días reservados exclusivamente para él o ella. Estos últimos, si uno de los padres decide no asumirlos, no pueden ser transferidos a la pareja. Hoy, los hombres en Suecia toman casi el 30 por ciento de todos los permisos parentales remunerados, una cifra que dentro de las políticas públicas se muestra como insuficiente. Al calcular, entre otras cosas, este beneficio parental, se utiliza el SGI, que determina la tasa de sustitución. SGI significa "ingresos calificados para beneficios por enfermedad". Es una cantidad calculada por la Agencia Sueca de Seguridad Social, que es la base de cuánto dinero puede recibir un ciudadano si enferma o solicita el permiso parental y se calcula sobre la base de un ingreso laboral anual estimado. Hay situaciones en las que una persona que no trabaja debe mantener sus ingresos basados en beneficios por enfermedad y esta protección SGI se aplica, por ejemplo, al desempleo, siempre que se esté registrado y se busque trabajo activamente a través del Servicio de Empleo. El beneficio parental está protegido durante los dos primeros años de vida del niño y no se ve afectado si sus ingresos calificados se reducen. Esto significa que incluso si los ingresos calificados son más bajos (por ejemplo, si reduce sus horas de trabajo), recibirá la misma cantidad de beneficio parental que antes si toma el permiso parental nuevamente antes de que el niño cumpla dos años de edad. Lo mismo se aplica en el caso de nuevo embarazo antes de que el niño mayor tenga un año y nueve meses; también recibirá el beneficio parental calculado utilizando los mismos ingresos calificados que antes de que se redujera.

Pese a los grandes avances logrados en Suecia, siempre a la vanguardia en políticas de conciliación y de igualdad de género, el último dato recogido anualmente por la Agencia Sueca de Seguridad Social refleja que aún existe una brecha de género entre quienes más se benefician de la asignación parental. Los siguientes datos lo refrendan: los hombres retiraron el 29 por ciento de la asignación parental (y se incorporaron antes a la vida laboral) y las mujeres retiraron el 71 por ciento ${ }^{19}$.

18 Lagen om allmän försäkring, AFL (La Ley sobre Seguros Generales, de 1962).

19 Datos de la Agencia Sueca de Seguridad Social que pueden consultarse vía online en https://www.forsakringskassan.se/ 


\section{Conclusiones}

En este artículo se describen y analizan las diversas políticas de empleo que han ido sucediéndose hasta lograr que las mancomunidades de municipios y los municipios sean prestadores de servicios de empleo. Hemos valorado la novedad de los consejos de seguridad laboral y del fuerte papel de los sindicatos en este país, analizando qué sectores son los prioritarios en cuanto a las estrategias de Empleo marcadas por el Servicio Público de Empleo. Vemos que la política de mercado de trabajo, que se apoya en el "principio de empleo", se diferencia de las políticas de muchos otros gobiernos dentro de la UE.

Por otro lado, hemos visto las políticas que han servido de apoyo a la conciliación laboral y familiar en Suecia, resaltando la figura de Alva Myrdal y el compromiso político en la política familiar, centrando sus trabajos en el feminismo y en la garantía del Estado de Bienestar.

Tras ello, se ha ido avanzando hasta el momento actual de reconocimiento y disfrute del permiso parental, además de otras cuestiones como la monoparentalidad y el derecho a la pensión alimentaria, entre otros, trazando diferencias con otras sociedades mencionadas.

La monoparentalidad ha sido cada vez más respaldada a través de diversas reformas legislativas que hemos ido analizando, valorándose a las familias monoparentales como estructuras familiares en las que un padre o madre debe hacer frente del cuidado de hijos menores de edad, atendiendo a situaciones especiales de vulnerabilidad económica y en las que diversos datos siguen constatando brechas de género. Las ayudas a las familias monoparentales tienen como fin dar la posibilidad de crear una situación familiar satisfactoria aunque falte uno de los dos miembros de la pareja y también conceden derechos a la pareja de cohabitación, aunque no haya un reconocimiento legal como cónyuge. La monoparentalidad constituye una estructura familiar donde no es posible la tradicional división sexual del trabajo en que se asentó el Estado de Bienestar después de la II Guerra Mundial. Analizando las políticas de apoyo más importantes habidas en las últimas décadas, quedan de relieve los avances en la institucionalización de la educación de los niños, su derecho al cuidado y las garantías para la participación activa de la mujer en el trabajo, sin menoscabo de sus derechos laborales por ser o no mujer casada, por estar embarazada o por ser madre.

Todo confirma a Suecia y a sus políticas como uno de los países pioneros en la lucha política por la conciliación, contra la discriminación de género, por una economía productiva inclusiva, por un porcentaje de desempleo bajo en comparación con otros países vecinos y con otros miembros de la OCDE y apostando decididamente por medidas de fomento de la natalidad y de protección de los derechos del niño.

\section{Bibliografía}

Björnberg U. y Eydal, G. (1995). “Family obligations in Sweden”. En Millar, J. ay Warman, A. (eds). Defining Family Obligations in Europe. Bath: University of Bath.

Carlson, C. (1990). Perspectives on the family: History, class and feminism. London: Wadsworth Publishing Co Inc.

Castles, F. y Flood, M. (1993). Why divorce rates differ, law, religious belief and modernity. Londres: Pluto Press.

E1 Instituto Sueco (2000 y ss.) Estadísticas y encuestas de opinión pública. Material de Swedish Institute, disponible en https:// si.se/en/

Esping-Andersen (1990). The three worlds of welfare capitalism. New Jersey: Princeton University Press

European Parliament (1997) Politica social y del mercado de trabajo en Suecia. Dirección General de Estudios. Documento de trabajo. Serie Asuntos Sociales. Disponible en: https:/www.europarl.europa.eu/workingpapers/soci/w13/summary_es.htm

Eurostat database (1995 y ss.) Disponible en https://ec.europa.eu/eurostat/data/database

Försäkringskassans (2020) Agencia Nacional de Seguridad Social. Información sobre el seguro parental en Suecia. Disponible en: https://www.forsakringskassan.se/privatpers/foralder/foraldraforsakringen45ar

Garfinkel, I. y Sörensen, A. (1982) Sweden's child support system: lessons for the United States. Oxford: Oxford University Press.

Goode, W. (1993). "World changes in divorce patterns", Population and Development Review, 20 (4): 899-901.

Gould, A. (1996). The last bastion of social democracy in "European welfare policy - squaring the welfare circle". London: Macmillan.

Haas, A. (1992). The role of the father in child development. London: Editado por Michael E. Lamb. Ed. John Wiley.

Hobson, B. y Takahashi, M. (1997) The parent-worker model: Lone mothers in Sweden. London: Sage.

Hoem. B y Hoem, J. (1993). "Public policy as the fuel of fertility. Effects of a policy reform on the pace of childbearing in Sweden in the 1980s", Acta Sociologica, 36: 19-31.

Hoem, B. y Hoem J. (1992). The disruption of marital and non-mantal unions in contemporary Sweden. Demographic applications of event history analysis. Oxford: Clarendon Press.

Lidgren, A. (2005) Mamma-, Pappa- eller barnledighet? En förmån och ett politiskt instrument Om ekonomisk ersättning vid föräldraledighet. Stockholms: Stockholms Universitet.

Liljeström, R. (1978). Roles in Transition. Suecia: LiberForlag.

Madruga, I. (2006). Monoparentalidad y política familiar. Madrid: CIS.

Maravall, J. (1995). Economic reforms in new democracies. Madrid: Alianza Editorial.

Myrdal, A. y Myrdal, G. (1934). Kris i befolkningsfrågan. Bokförlaget Nya Dox.

OECD Economic Surveys-Sweden (1994). Disponible en: https://www.europarl.europa.eu/workingpapers/soci/w13/summary_ es.htm

Olsson, S. (1993). Social policy and Welfare State in Sweden. Lund: Arkiv.

Popenoe, D. (1988). Social institutions and social change. Disturbing the nest: Family change and decline in modern societies. Aldine de Gruyter. 
Ruggie, M. (1984) The state and working women: A comparative study of Britain and Sweden. Princenton: Princeton University Press.

Rundström, M. (2000) Kommuner som utförare av tjänster åt Arbetsförmedlingen - en analys av de rättsliga förutsättningarna. Disponible en: https://www.regeringen.se/

Skedinger, P. (1995). “La política sueca de mercado laboral: ¿remedio al paro?”, Revista CEDEFOP, 2 (94): 28-32.

Statistikmyndigheten SCB (2020). Base de Estadisticas de Suecia, scb.se

Stephens (1996) The comparative political economy of the Welfare State. New York: Cambridge University Press.

Sundström, M y Duvander, A.Z. (1992). "Gender division of childcare and the sharing of parental leave among new parents in Sweden", European Sociological Review, 18 (4): 433-447.

Sundström, M. y Stafford, F. (1992). "Female labor force participation, fertility and public policy", European Journal of Population, 8 (3): 199-215.

Therborn, G. (1993). “The politics of childhood”. En Castles, F. (ed.), Families of Nations: Aldershot: Dartmouth.

Thobson B. y Takahashi, M. (1997). The parent-worker model: Lone mothers in Sweden. London: Jessica Kingsley Publishers.

Vicente, M. J. (2019). La Premio Nobel Alva Myrdal, su proyecto social y su apuesta”, Nueva Tribuna, 28 de noviembre. Disponible en: https://nuevatribuna.publico.es/articulo/global/premio-nobel-alva-myrdal-proyecto-social-apuesta-paz/20191128114509168618.html

Wennemo, I. (1994). "Infant mortality, public policy and inequality-a comparison of 18 industrialised countries 1950-85", Sociology of Health and Ilness, 14 (4): 429-446. 